\title{
Development of a Structural Integrity Non-destructive Inspection System for Bridges Made of Weathering Steel
}

\author{
Björn Torsten Salmen ${ }^{1}$, Marina Knyazeva ${ }^{1}$ and Frank Walther ${ }^{1}$ \\ ${ }^{1}$ WPT, Department of Materials Test Engineering, 44227 Dortmund, Germany
}

\begin{abstract}
Due to the increasing volume of traffic, bridges are exposed to higher loads as it was considered during the planning phase. Therefore, a regular inspection is necessary in order to detect cracks at very early stages. The use of weathering structural steel in bridges, as well as in composite bridge constructions is an alternative to conventional bridges, not only from an economic but also from an ecological point of view, since it is not necessary to apply a corrosion protection layer and renew it during the lifetime of the bridge. Unfortunately, conventional visual inspection or magnetic particle inspection on the weathering steel bridge are hindered by the protective patina and requires development of new test methods. Within the framework of this project, a combined crack detection technique using non-destructive inspection by means of Active Thermography and by Electro-Magnetic Acoustic Transducer (EMAT) were evaluated in laboratory environments and in real conditions on bridge structures made of weathering structural steel.
\end{abstract}

\section{Introduction}

Nowadays, there is an increased focus on environmental protection of bridges, and their construction efficiency. Many bridges made of steel and steel-composites exhibit considerable defects, reducing the bearing capacity. Around $20-25 \%$ of the municipal bridges in Germany present renewal requirements [1].

Conventional bridges made of structural steel must be provided with an organic corrosion protection, which must be renewed at least two times during the life cycle of the bridge. To achieve this, the old protection layer must be removed using air- or sandblasting and the new protection coat must be applied. This requires a considerably high financial and environmental load, which can be overcome using weathering structural steels [2], [3].

Weathering steel possesses improved resistance to atmospheric corrosion compared to conventional structural steels owing to the formation of a protective rust patina layer on its surface. The stable rust layer develops and regenerates continuously under the influence of the weather, leading to very slow rates of atmospheric corrosion. Since the weathering steels develop a thick and firmly adhered patina layer, no application of any corrosion protection is necessary. In this way, the use of weathering steel is profitable from economical point of view and initial surcharges are insignificant considering future savings in corrosion protection. Bridge constructions must be examined, as a rule, every two to three years, more comprehensive inspections must take place every six to ten years.
Through a visual inspection of conventional bridges, a possible crack could appear as rust stain on the corrosion protection paint. For detected cracks, more precise inspection can be carried out using non-destructive material testing, for example, the dye-penetrant technique or magnetic particle inspection. For constructions made of weathering structural steels these methods are not applicable, since the possible cracks are covered by the protection rust layer and therefore are not visually detectable.

The main goal of this work is the development of new method for detection of cracks under protective cover layers, specifically below the compact patina of weathering steel, using a novel combination of nondestructive measuring procedures, namely the ElectroMagnetic Acoustic Transducer (EMAT) System and the Active Thermography. The EMAT ultrasonic testing is a widely used procedure to test pipelines, making possible the detection of cracks within a depth of $10 \%$ of the material thickness. Additionally, the non-contact EMAT system can be applied to analyse cracks on railroad tracks and tires [4], [5]. These topics have been broadly investigated by several research groups [6] - [9]. Active Thermography has been used for crack detection on die forged parts, where a disturbed heat flux around the crack makes it visible. Further applications are in-line testing of metal sheets and wires, where thermography has already yielded promising results in crack detection [10], [11].

\section{Material}


The tests were performed on specimens and bridges made of weathering structural steel S355J2W (Tab.1).

Table 1. Chemical composition of weathering structural steel.

\begin{tabular}{|c|c|c|c|c|}
\hline $\mathrm{C}$ & $\mathrm{Si}$ & $\mathrm{Mn}$ & $\mathrm{Mo}$ & $\mathrm{P}$ \\
\hline$<0.16$ & $<0.5$ & $0.5-1.5$ & $<0.3$ & $<0.03$ \\
\hline $\mathrm{S}$ & $\mathrm{Cu}$ & $\mathrm{Cr}$ & $\mathrm{Zr}$ & $\mathrm{Ni}$ \\
\hline$<0.03$ & $0.25-0.55$ & $0.4-0.8$ & $<.015$ & $<0.65$ \\
\hline
\end{tabular}

\section{Experimental approach}

Two non-destructive methods were tested: Active Thermography and Electro-Magnetic Acoustic Transducer (EMAT). For the first evaluation of the both inspection techniques, tests were carried out in the laboratory on the specimens with ground blank surface. The bulk specimens for the laboratory test were notched and cyclically loaded in 3-point bending test until a deep crack occurred. In addition, the sensitivity of EMAT technique was evaluated on a specimen with three surface scratches $0.1,0.3$ and $0.5 \mathrm{~mm}$ depth, respectively.

After testing of the blank grinded samples with thermography and EMAT, an artificial rust patina was produced on the specimen surface, and the measurements were performed again in order to verify the influence of protective patina on crack detection be means of both analytic systems. In order to accelerate the oxidation, the samples were immersed in dilute nitric acid for 20 hours. The thickness of the patina layer was measured on a cross-section of corroded specimen via optical microscopy. The previously distinctive visible crack was almost completely covered by the corrosion layer and was no longer visible to the naked eye, establishing the most difficult boundary conditions for crack detection. On this way, it was possible to simulate the cover layer of weathering structural steel and perform the experiments under worst-case conditions.

Further evaluation of the measuring technique was continued on a bridge made of weathering structural steel. Since the bridge did not show any cracks, the measurements were performed for assessment of the technique's limitations in real environment.

\subsection{Active thermography}

The physical principle of active thermography is based on an induction of the heat flow by an external energetic source. Defects in the material influence the emitting heat flux, whereby the inhomogenities can be detected on the surface of the test object with a high-precision thermographic camera. By application of various evaluation algorithms for signal amplification a significant improvement of the signal-to-noise ratio can be achieved, whereby broad range of material defects can be detected.

The camera thermoIMAGER 160, built by MicroEpsilon Messtechnik, was used for Active Thermography measurements. The control of the camera and the evaluation of the acquired images were carried out by the software TIMConnect. The specimens were heated up using an infrared radiator up to about $40{ }^{\circ} \mathrm{C}$ and analyzed during the heating, as well as during the cooling phase. The heating time were varied between $30 \mathrm{~s}$ and $60 \mathrm{~s}$, the viewing angle between 0 and $20^{\circ}$, and the recording intervals, between 10 and $80 \mathrm{~s}$. The measurement data were recorded as video. The same series of experiments were carried out on the corroded specimen.

\subsection{Electro-Magnetic Acoustic Transducer System (EMAT)}

On the same specimens were performed the measurements by means of EMAT test system, type SonaFlex from producer Nordinkraft.

The technique is based on an ultrasonic wave propagating along the surface using electro-magnetic mechanisms for non-contact sound generation and reception. Similar to ultrasonic non-destructive testing, the EMAT-system operates by inducing and receiving of acoustic waves, induced in ferromagnetic material using two interacting magnetic fields. A high frequency field generated by electrical coils interacts with a permanent magnet generates a Lorentz force, producing an elastic wave. The reflections, caused by the interaction of ultrasonic waves with defects, will be received by a second coil placed in the EMAT-sensor. In contrast to conventional ultrasonic test methods, it is a non-contact method, which means no coupling medium is required. The measurements were performed with frequency of 1 $\mathrm{MHz}$ and analyzed by UTE software developed by Nordinkraft.

\section{Results}

\subsection{Laboratory experiments}

All the test parameters of thermography measurements provide consistently reliable results. Figure 1 gives an overview of the test specimen with deep crack for evaluation of non-destructive testing in lab environment.

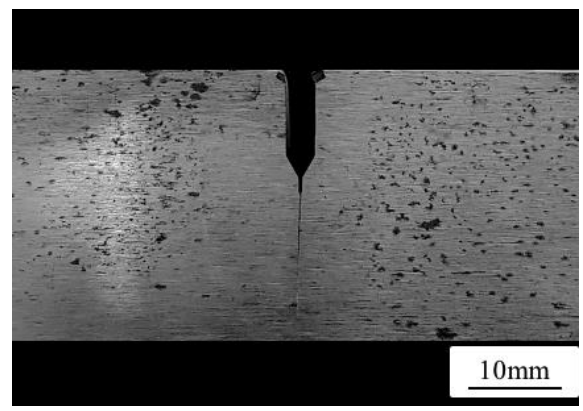

Figure 1. Overview of the blank test specimen with deep crack.

Figure 2 shows an image taken with thermography camera after 30 s heating and 10 s cooling at a viewing angle of $0^{\circ}$. Due to the interrupted heat flow, the crack appears as a cooler area with temperature difference to specimen surface about $3-4{ }^{\circ} \mathrm{C}$ and can be easily recognized at every stage of heating and cooling. 
Thermographic tests on the uncorroded samples show that the variation of heating time with an infrared emitter has a small influence on the detectability of the crack. A prolonged heating has advantage of deeper heating of the steel surface and leads to a longer time slot for crack detection due to longer cooling time. Viewing angle does not affect the detectability of the crack.

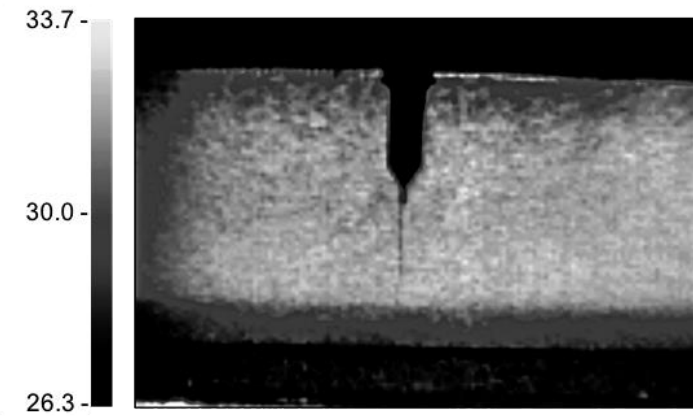

Figure 2. Thermography image of the blank test specimen.

The evaluation of EMAT technique sensitivity has shown what all cracks with a depth more as $0.3 \mathrm{~mm}$ can be easily detected. In order to verify the gained results by active thermography, the EMAT crack detection were performed on the same specimens.

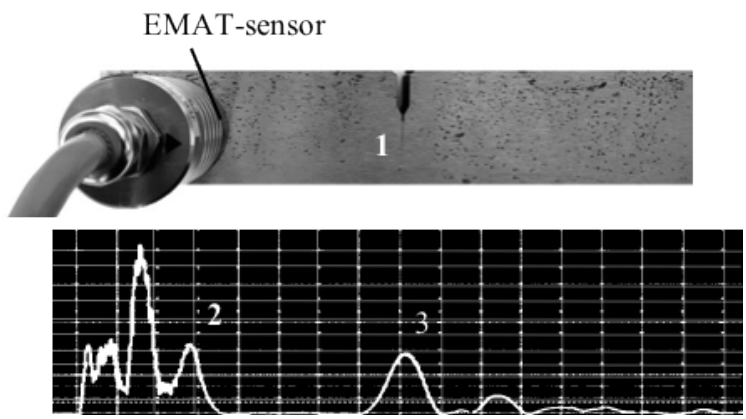

Figure 3. EMAT-scan of the blank test specimen from Fig. 1.

As it can be seen at the scan in Figure 3, the crack (1) can be clearly recognized as a significant peak of the ultrasonic waves echo (3) occurred at the crack. Also visible is the coupling echo (2), generated by the sensor itself. The scan does not show a back wall echo because of wide gap between crack walls.

The measurements were repeated on the corroded samples. The crack was completely covered by corrosion product and not recognizable with the naked eye, the thickness of the corroded layer was measured in a crosssection as $19-29 \mu \mathrm{m}$.

Figure 4 shows the thermography image of the corroded specimen taken immediately after 30 s heating (cooling time 0s), providing best contrast due to the highest temperature gradient. The previously very well detectable crack is no longer visible. A prolonging heating time as well as variation of the viewing angle did not lead to any significant changes. Similarly, varying the temperature profile from 40 to $70{ }^{\circ} \mathrm{C}$ did not lead to any improvement. It has been found that the thermal conductivity of the patina layer is very low, disrupting the heat flux and decreasing the possibility of crack detection. The different grey scale rendering can be explained by the difference in the layer thicknesses. Two visible strips
(A and B) in the Figure 3 correspond with substantially thinner corrosion layer, which indicates an insulating effect of the patina. Moreover, due to the low thermal conductivity of the patina layer, the emitted infrared radiation is diffused. The reason lies on the one hand in the diffusely reflected IR radiation in comparison to blank surface, and, on the other hand, the radiation emitted by the sample itself distributes more uniformly.

Therefore, the crack detection via thermography on a mechanically unloaded specimen with a thick corrosion layer in static state is not possible without removing the patina or reducing its thickness by means of brushing. The test has to be repeated for crack detection on a real bridge in order to obtain more reliable results of application under realistic condition.

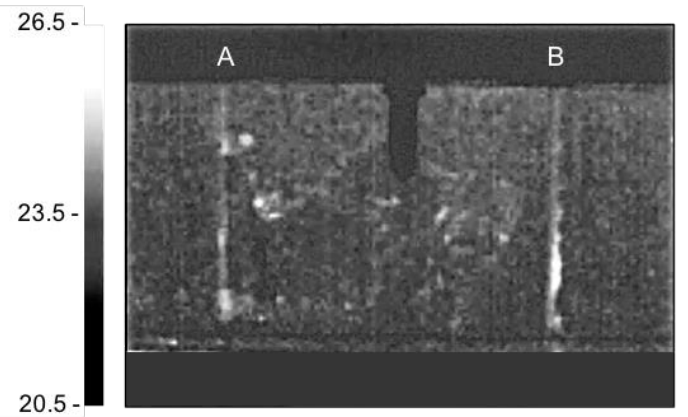

Figure 4. Thermography image of the corroded test specimen.

The EMAT testing on the same corroded specimen continued to provide significant crack detection (Figure 5). Since the ultrasonic wave is directly generated within the material by electromagnetic field induction, the thick corrosion layer had no influence on the ultrasonic signal of the EMAT-test system. It can be clearly seen, that the crack (1) under the patina layer is still evidently visible in the scan next to the coupling echo (2) as a significant peak (3). Furthermore, it can be seen that the signal is forwarded through the corroded crack to the end of the specimen. Another peak (4), caused by the back wall echoes appears at the position correlating with the end of the specimen. In practice, this would have the advantage that the signal propagates over a greater range and so measurements can be carried out efficiently.

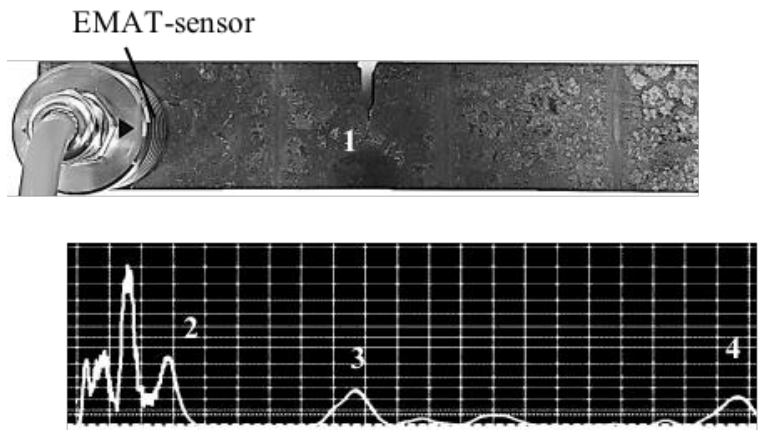

Figure 5. EMAT-scan of the corroded test specimen.

\subsection{Experiments on the bridge}


Both the active thermography and the EMAT inspection system were tested on bridge made of weathering steel. The bridge inspection was carried out at the temperature of $+4{ }^{\circ} \mathrm{C}$. The bridge consists of main carrier segments joined by butt weld, and T-joint with double fillet weld between the main beam and cross beams. The aim of the experiments was to prove the boundary condition of techniques applications in order to recognize possible challenges for systems operation in non-laboratory environment. The bridge itself does not have any cracks, which was proved via magnetic particle inspection on ground joint connections in the areas experiencing the highest operational load.

No influences caused by the low temperature or by the patina layer on the crack detection via EMAT were detected. For the bridge inspection the EMAT-signal must be amplified till the weld seam echo obtains visible. Thus the coupling echo (1) appears much higher than in the scans of lab specimens. The EMAT testing showed significant impact of surface geometry, as is the case with fillet welds. Already at the fusion zone of the weld seam, a reflection of the ultrasonic waves occurs (2), the width of the welding seam corresponds to the width of the peak.

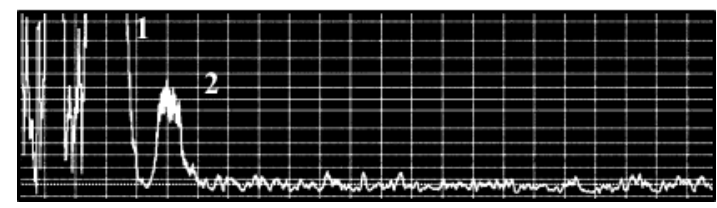

Figure 5. EMAT-scan of fillet weld seam of the weathering steel bridge.

The challenge of thermography application in real conditions was relatively low environment temperature up to $+4{ }^{\circ} \mathrm{C}$, leading to prolonged heating time. In order to avoid any impact on material due to testing, the maximal temperature was restricted to $+80^{\circ} \mathrm{C}$. After approximately 2-3 minutes it was possible to achieve a uniform heat distribution on the surface of interest area and acquire viable images. The T-joint geometry was another challenge for thermography, causing the appearance of shadows and making the crack detection more difficult. The problem can be solved by taking a video of the area of interest with slow movement of the camera in different directions and with a broad angle variation, in order to acquire the most complete information and minimize the influence of shadows in static image.

\section{Conclusion}

To take advantage of the use of weathering steel, it is necessary to develop safe and reliable non-destructive test methods. The Electro-Magnetic Acoustic Transducer (EMAT) and the Active Thermography testing, evaluated in this study, are well suited for non-destructive inspection, especially in combination.

Laboratory tests of both testing methods have provided significant and reliable results on blank uncorroded specimens with grinded surface. The cracks were perfectly visible on thermography images as well as on EMAT-scans. The limits of active thermography were shown at the severely corroded specimen, where it was no longer possible to detect a crack due to insulation properties of thick corrosion layer. Remedy could be achieved by reducing the thickness of the patina using brushing. The EMAT system, however, was not affected by the corrosion layer and provided significant and reliable results. The crack detectability on the corroded surface remains the same as on the blank grinded surface.

The inspection of the welding seams on the bridge were of limited significance, as all tested seams showed no crack and therefore no statement can be made about crack detection. In order to validate the accuracy and reliability of the methods, further tests on weathering steel bridges possessing cracks are required. The influence of geometry of welding seams on the signal of the EMAT system, maximum distance to the crack as well as detectability of inner defects has to be further investigated. Due to the fact that the thermography provided poor results on severely corroded lab specimens, the limits of the test method and suggested remedy should be approved in real conditions.

\section{References}

1. Ersatzneubau Kommunale Straßenbrücken, DIfU Deutsches Institut für Urbanistik, Berlin, 2013.

2. M. Fischer, Merkblatt 434: Wetterfester Baustahl, Düsseldorf: Stahl-Informationszentrum, 2004.

3. M. Fischer und U. Roxlau, Anwendung Wetterfester Baustähle im Brückenbau, Forschungsbericht Projekt 191, Studiengesellschaft Stahlanwendung e.V., Düsseldorf, 1992.

4. M. Hirao, H. Ogi, H. Fukuoka. (April 2009). Advanced ultrasonic method for measuring rail axial stresses with electromagnetic acoustic transducer, Res. Nondest. Eval., 5, pp. 211-223.

5. J.L. Rose, M.J. Avioli, P. Mudge, R. Sanderson. (October 2003), Guided wave inspection potential of defects in rail, NDT \& E Int., 37, pp.153-16.

6. M. Junger, H.M. Thomas, R. Krull, Wirbelstromprüfung betriebsbedingter Schädigung an Eisenbahnbrücken, Stahl Eisen, 119, Düsseldorf 1999, pp. 107-110.

7. di Scalea, F. Lanza., J. McNamara, Ultrasonic NDE of railroad tracks: Air-coupled cross-sectional inspection and long-range inspection, Insight, 45, Juni 2003, pp. 394-401.

8. S. Kenderian, D. Cerniglia, B. Boro Djordjevic, et al., Rail track field testing using laser/air hybrid ultrasonic technique, Mater. Eval. 61, December 2002, pp- 1129-1133.

9. R. Pohl, A. Erhard, et al., NDT techniques for railroad wheel and gauge corner inspection, March 2004, NDT \& E Int., 37, pp. 89-94.

10. K. Ehrig, D. Meinel, P. Myrach, A. StranzingerMayrhauser, M. Ziegler, "CT als Referenz zur thermographischen Untersuchung von Defekten im gesenkgeschmiedeten Stahl“, DGZfP- Jahrestagung 2013 - Di.2.A.

11. B. Oswald-Tranta, (April 2012), "Thermografische Rissdetektion auf glühendem Draht während des 
Walzprozesses mit Hinblick auf Ausschussreduzierung", Berichte aus Energie- und
Umweltforschung. 